\title{
Altitude dependence of polychlorinated biphenyls (PCBs) and polybrominated diphenyl ethers (PBDEs) in surface soil from Tibetan Plateau, China
}

\author{
Pu Wang, Qinghua Zhang*, Yawei Wang, Thanh Wang, Xiaomin Li, Yingming Li, Lei Ding, Guibin Jiang \\ State Key Laboratory of Environmental Chemistry and Ecotoxicology, Research Center for Eco-Environmental Sciences, Chinese Academy of Sciences, Beijing 100085, China
}

\section{A R T I C L E I N F O}

\section{Article history:}

Received 15 April 2009

Received in revised form 16 June 2009

Accepted 18 June 2009

Available online 22 July 2009

\section{Keywords:}

Persistent organic pollutants

High mountain areas

Surface soil

Long range transport

Gradient distribution

\begin{abstract}
A B S T R A C T
Remote mountain areas besides high latitude regions are beginning to receive increased attention in studying the transport and behavior of persistent organic pollutants (POPs). In the present work, surface soil samples were collected from the Tibetan Plateau, the highest plateau in the world which includes the northern slope of Mt. Qomolangma, to investigate the levels and trends of polychlorinated biphenyls (PCBs) and polybrominated diphenyl ethers (PBDEs) along the altitudinal gradient. The average PCB and PBDE concentrations were $185.6 \mathrm{ng} \mathrm{kg}^{-1}$ dry weight (dw) (range 47.1-422.6 ng kg-1 dw) and $11.1 \mathrm{ng} \mathrm{kg}^{-1} \mathrm{dw}$ (range 4.3-34.9 $\mathrm{ng} \mathrm{kg}^{-1} \mathrm{dw}$ ), respectively. Regression analysis between the log-transformed TOC-normalized concentrations and the altitudes of the sampling sites showed two opposite trends with regard to altitude dependence: negative relationship with altitude below about $4500 \mathrm{~m}$ followed by a positive altitude dependence above this point. Considering minimum anthropogenic activities and very sparse precipitation in the north of Himalayas, the trends above $4500 \mathrm{~m}$ imply that the significant altitude dependence of these two groups of POPs were irrespective of pollution sources, but could be predicted by the global distillation effect involving cold condensation in high altitude mountain areas. Increasing levels of heavier congeners were found in higher altitude sites, although the lighter congeners were the main contributors to the total amount, suggesting that less volatile congeners seem to become enriched easier than those more volatile at higher altitudes in this region.
\end{abstract}

(c) 2009 Elsevier Ltd. All rights reserved.

\section{Introduction}

Polychlorinated biphenyls (PCBs) and polybrominated diphenyl ethers (PBDEs) share many similar physicochemical properties. As two groups of persistent organic pollutants (POPs), they are toxic, bioaccumulative, and can undergo long-range atmospheric transport (LRAT) from polluted environments to pristine areas far away from any anthropogenic activities. Although PBDEs were produced much later than PCBs, they have already been ubiquitously found in the environment.

Remote regions with cold climate are prone to enrich POPs through global fractionation and cold condensation (Wania and Mackay, 1993; Simonich and Hites, 1995). Several studies in high latitude regions, including the Arctic (Clausen and Berg, 1975; Gregor and Gummer, 1989; Ikonomou et al., 2002) and Antarctic (George and Frear, 1966) revealed the widespread distribution of these chemicals. Recent studies have also been focusing on mountain areas at high altitude to investigate the levels of POPs in these pristine environments and the extent of POPs to undergo LRAT (Daly and Wania, 2005; Loewen et al., 2005; Chen et al., 2008;

\footnotetext{
* Corresponding author. Tel./fax: +86 1062849818.

E-mail address: qhzhang@rcees.ac.cn (Q. Zhang).
}

Wania and Westgate, 2008; Shen et al., 2009). Daly and Wania (2005) indicated that the more volatile pollutants seem to become enriched with higher altitudes to a larger extent relative to those less volatile. But for some selected contaminants, concentration inversions (i.e., increasing concentrations with elevation) have been observed (Fernández and Grimalt, 2003; Borghini et al., 2005).

The Tibetan Plateau, located in the southwest of China, is the highest plateau in the world. It is considered as the third pole because of its unique meteorological and geographic characteristics. Mt. Qomolangma (also named as Mt Everest, $8844.43 \mathrm{~m}$ above sea level, $m$ a.s.l.) wedged in between China and Nepal represents the highest peak in the Himalayas and the world. Except for occasional expeditions by adventurers and explorers, no evident human activities exist in this area. It is therefore an ideal place to investigate the influence of altitude and other orographic parameters on the distribution of POPs in high mountains. However, a very limited number of studies have been conducted in this region on POPs including organochlorine pesticides (OCPs), and polycyclic aromatic hydrocarbon (PAHs) (Wang et al., 2006, 2007a,b; Yang et al., 2007).

The objective of this study was to investigate the levels and distribution patterns of PCBs and PBDEs in surface soil from the central and southwest of Tibetan Plateau including the northern slope 
of Mt. Qomolangma. The altitudinal distribution trends and temperature dependence were also statistically analyzed and discussed.

\section{Materials and methods}

The materials used in this study are described in detail in the Supplementary material.

\subsection{Sampling}

All the soil samples were collected during a scientific exploration to Mt. Qomolangma by the Chinese Academy of Sciences in March and April 2005. The sampling locations, as shown in Fig. 1 , are located between $28.035^{\circ} \mathrm{N}$ and $30.093^{\circ} \mathrm{N}, 86.943^{\circ} \mathrm{E}$ and $90.926^{\circ} \mathrm{E}$. Eleven surface soil samples were collected at the depth of $0-15 \mathrm{~cm}$ along the highway from Yambajan (sampling site 1) to Nyalam (sampling site 10), four moraine soil samples were obtained from the northern slope of Mt. Qomolangma. At each site, multiple soil samples were collected using a stainless steel spade and combined to form a composite sample for the site. Samples were sealed in the clean plastic bags, transported to the laboratory and stored frozen $\left(-20^{\circ} \mathrm{C}\right)$ until extraction.

\subsection{Sample extraction and analysis}

Sample extraction, cleanup and chemical analysis followed our previously established method with some modifications (Liu et al., 2006). Detailed procedures are given in the Supplementary material. Quantification was processed for 14 PBDE congeners (BDE$17,28,47,66,71,85,99,100,138,153,154,183,190$ and 209) and 25 PCB congeners which include 12 dioxin-like congeners (PCB-77, 81, 105, 114, 118, 123, 126, 156, 157, 167, 169, and 189), six indicator congeners (PCB-28, 52, 101, 138, 153, and 180 ), and other congeners (PCB-3, 15, 19, 202, 205, 208, and
209). The total concentration of all congeners in an individual homolog was calculated based on GC retention-time window definition. The analytical results were obtained based on an isotope dilution method using high-resolution gas chromatography coupled with high-resolution mass spectrometry (HRGC/HRMS). Total organic carbon (TOC) contents were analyzed on a TOC Analyzer (O.I Analyzer, College Station, TX, USA). About $0.1 \mathrm{~g}$ sample was weighed and loaded into the combustion cup which was packed with quartz wool. Prior to combustion, the samples were wet with $5 \%$ phosphoric acid and heated at $250^{\circ} \mathrm{C}$ for $1 \mathrm{~min}$ to purge the inorganic carbon. The signal was detected by non-dispersed infrared (NDIR) detection when flashed at $900{ }^{\circ} \mathrm{C}$ for $6 \mathrm{~min}$ in the combustion house.

\subsection{Quality assurance/quality control (QA/QC)}

The limits of detection (LOD) of the analytical method were defined as signal-to-noise ratio $(\mathrm{S} / \mathrm{N})=3: 1$ and the isotopic ratios between the two main ion pairs were within $\pm 15 \%$ of the theoretical value. In this study, the LODs for PCBs and PBDEs were lower than $0.08 \mathrm{ng} \mathrm{kg}^{-1}$ and $0.34 \mathrm{ng} \mathrm{kg}^{-1}$, respectively, except for BDE-209, which was $11.1 \mathrm{ng} \mathrm{kg}^{-1}$ in average. All the samples were spiked with US EPA defined 68A-LCS (for PCBs) and PBDE-LCS $\left({ }^{13} \mathrm{C}-\mathrm{BDE}-47,99,153\right)$ for quantification and 68A-IS for recovery calculation. The recoveries of 68A-LCS and PBDE-LCS were in the range of $70-143 \%$ and $39-110 \%$, respectively, which satisfied the analytical demand. A sample of XAD sealed in a plastic bag was used as travel blank to monitor the contamination, and two laboratory blanks were processed paralleled with the soil samples for quality control. Analytical results showed that no contaminants were found in the XAD. In the laboratory blanks, PCB-28 and BDE-47 were detected at $<15 \%$ of their concentrations in the soil samples, while other compounds were not detected. The reported concentrations were therefore not corrected for the laboratory blanks.

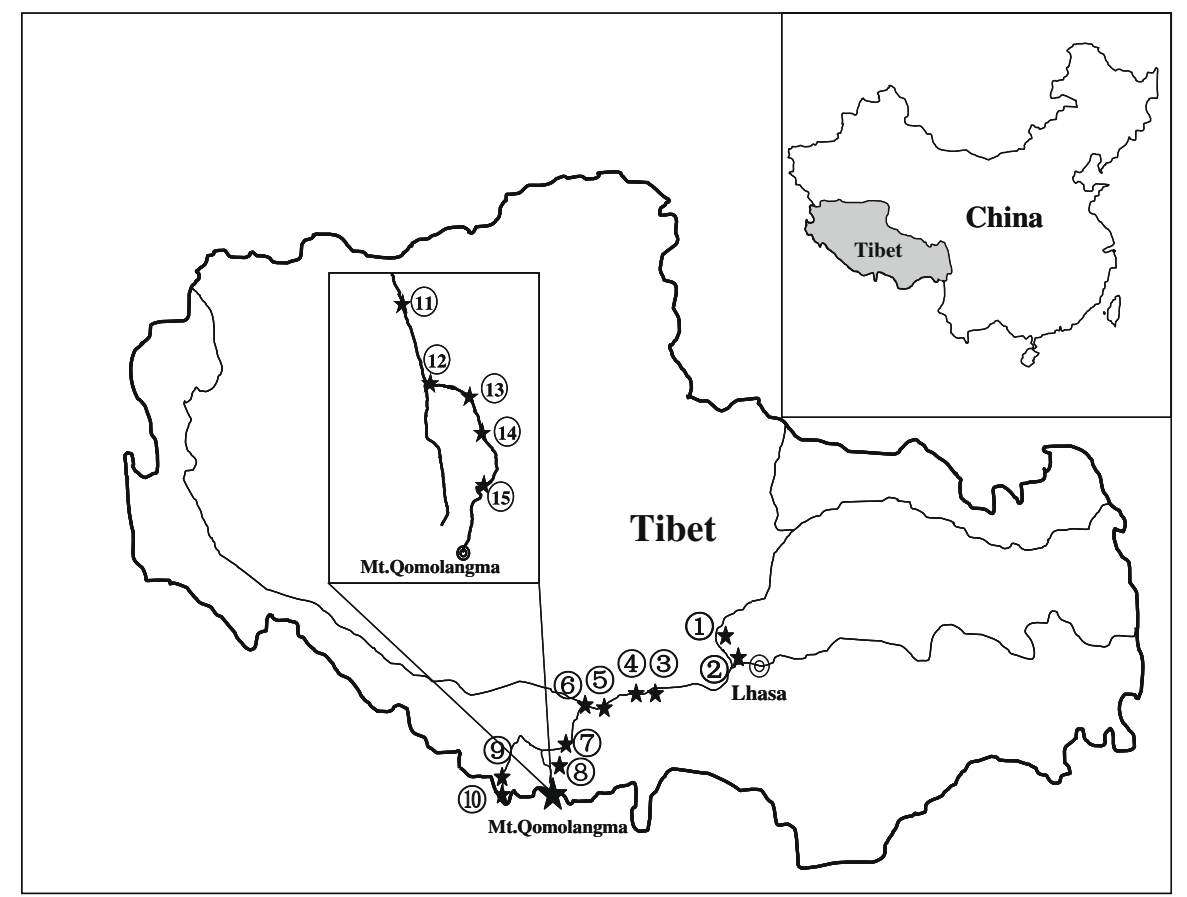

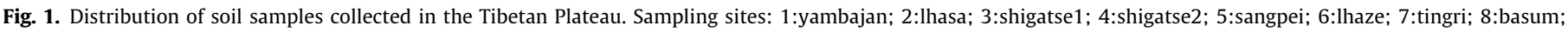
9:ximu; 10:nyalam; 11:base camp (BC); 12:east Rongbuk1; 13:east Rongbuk2; 14: middle base camp (MBC); 15: advance base camp (ABC). 


\section{Results and discussion}

\subsection{Geographic characteristic and meteorological condition}

As the highest plateau in the world, Tibetan Plateau has an average altitude of $4000 \mathrm{~m}$ a.s.l. and an area of 2.5 million $\mathrm{km}^{2}$. The climate is subject to typical southwest or summer monsoon (JuneSeptember) and winter westerly circulation (December-April). In the summer, the comparatively cool humid air mass developed from the southern hemisphere results in significant precipitation events in the southeast of Tibetan Plateau, which is the lowest part of the plateau. The southwest area, including the north of Himalayas, is situated in the rain shadow of the mountain and receives very little precipitation, and exhibits a decreasing trend from the central plateau to the north of Himalayas (Yang et al., 2006). In winter, air movement in the Tibetan Plateau is dominated by prevailing continental westerly wind, which results in dry cold climate and few precipitation events. The annual average atmospheric temperature maintains at the level of $8^{\circ} \mathrm{C}$ for the entire plateau. In Mt. Qomolangma region, the temperature is usually below $0{ }^{\circ} \mathrm{C}$ with a decreasing gradient of $0.8{ }^{\circ} \mathrm{C} / 100 \mathrm{~m}$ with increasing elevation (Ye and Gao, 1979). Thus, the transport and distribution of POPs in Tibetan Plateau are expected to be influenced by this unique orographic and meteorological system.

\subsection{Total organic carbon}

In general, the surface soil in Tibetan Plateau was very sterile (Table. 1). TOC was in the low range of $2.0-4.7 \mathrm{mg} \mathrm{C} \mathrm{g}^{-1}$ in the moraine soil in Mt. Qomolangma. In the agricultural soil, meadow soil and upland soil samples, average TOC was $17.8 \mathrm{mg} \mathrm{C} \mathrm{g}^{-1}$ (range 10.3-27.0 $\mathrm{mg} \mathrm{C} \mathrm{g}^{-1}$ ). This is in agreement with the results of Wang et al., (2007a).

\subsection{The concentrations of PCBs and PBDEs}

The concentrations of $\sum$ PCBs and $\sum$ PBDEs are listed in Table 1. The average concentration of $\sum$ PCBs in 15 soil samples was $185.6 \mathrm{ng} \mathrm{kg}^{-1} \mathrm{dw}$ (47.1-422.6 $\left.\mathrm{ng} \mathrm{kg}^{-1} \mathrm{dw}\right)$, which was similar to another work (Tibet, $138 \mathrm{ng} \mathrm{kg}^{-1}$, Ren et al., 2007) and within the level of global background surface soils $\left(26-97,000 \mathrm{ng} \mathrm{kg}^{-1} \mathrm{dw}\right.$, Meijer et al., 2003), but lower than the results from other remote mountain regions (Ribes et al., 2002; Grimalt et al., 2004; Borghini et al., 2005). Seven indicator congeners were evidently detected in all samples (Table $\mathrm{S} 1$ ), which accounted for about $13 \%$ of $\sum$ PCBs. PCB-28 was the dominant congener (average $70 \%$ of the indicator PCBs) and PCB-77, and 118 were the main contributors to the dioxin-like PCBs. The sum of the low-level chlorinated congeners (mono-, di-, tri- and tetra-CBs) accounted for more than $90 \%$ of $\sum$ PCBs (Fig. S1), which might indicate that the lighter PCBs are more prone to LRAT (Fernández and Grimalt, 2003).

The concentrations of $\sum$ PBDEs were in the range of 4.3$34.9 \mathrm{ng} \mathrm{kg}^{-1} \mathrm{dw}$ with an average at $11.1 \mathrm{ng} \mathrm{kg}^{-1} \mathrm{dw}$, which were much lower than other studies on remote areas, such as European background soils (0.065-12.0 $\mathrm{ng} \mathrm{g}^{-1} \mathrm{dw}$, Hassanin et al., 2004) and Russian Arctic (0.16-0.23 $\mathrm{ng} \mathrm{g}^{-1} \mathrm{dw}$, de Wit et al., 2006). BDE-47 was the main congener, accounting for about $40 \%$ of $\sum$ PBDEs, followed by BDE-28 (20\%) and BDE-99 (10\%) (Fig. S2). BDE-209 was not detected in any of the samples.

From these results, it could therefore be stated that PCBs and PBDEs levels investigated in the central and southwest of Tibetan Plateau, especially in Himalayan region which is remote from direct influence of anthropogenic sources, were at the low end in a global perspective and could be used as representative of soil background levels in the mid-latitude Northern Hemisphere.

\subsection{Effect of the total organic carbon content}

SPSS 13.0 and Origin 7.5 were employed for statistical analysis of the data. As supplied in Tables S2 and S3, the congener concentrations were significantly correlated between any two sites, which indicated that no punctual pollution episodes existed to disrupt their common geographical distribution pattern and long-term accumulation of POPs occurred in this area. We analyzed the relationships between the each congener concentrations and TOC in soil samples from these 15 sampling sites, and significant correlations $(p<0.05)$ were observed for most congeners between logtransformed congener concentrations (except for PCB-180 and 209) and $\log$ (TOC) (Table 2). These good correlations between congener concentrations and TOC suggested that the geographical distribution pattern of these compounds in the sampling region might be approaching steady state with soil properties since there is absence of punctual pollution episodes, which have also been discussed in previous works regarding organochlorine compounds (OCs) in soil from Teide Mountain, Canary Island (Ribes et al., 2002) and Andean Mountains, Chile (Borghini et al., 2005). This

Table 1

Information on sampling locations, soil samples and the concentrations of PCBs and PBDEs.

\begin{tabular}{|c|c|c|c|c|c|c|c|c|c|c|}
\hline No. & Sampling site & Soil type & $\begin{array}{l}\text { Latitude } \\
\left({ }^{\circ} \mathrm{N}\right)\end{array}$ & $\begin{array}{l}\text { Longitude } \\
\left({ }^{\circ} \mathrm{E}\right)\end{array}$ & $\begin{array}{l}\text { Altitude } \\
\left(\mathrm{m} \text { a.s.l. }{ }^{\mathrm{a}}\right)\end{array}$ & $\begin{array}{l}\text { Temperature } \\
\left({ }^{\circ} \mathrm{C}\right)\end{array}$ & $\begin{array}{l}\text { Precipitation } \\
\left(\mathrm{mm} \mathrm{y}^{-1}\right)\end{array}$ & $\begin{array}{l}\text { TOC } \\
\left(\mathrm{mg} \mathrm{C}^{-1}\right)\end{array}$ & $\begin{array}{l}\left.\sum_{(\mathrm{PCBS}} \mathrm{kg}^{-1} \mathrm{dw}\right)\end{array}$ & $\begin{array}{l}\sum \text { PBDEs } \\
\left(\mathrm{ng} \mathrm{kg}^{-1} \mathrm{dw}\right)\end{array}$ \\
\hline 1 & Yambajan & Meadow soil & 30.093 & 90.498 & 4305 & $1.3^{\mathrm{c}}$ & $456.8^{\mathrm{c}}$ & 18.7 & 155 & 10.5 \\
\hline 2 & Lhasa & Agricultural soil & 29.675 & 90.926 & 3689 & $8.01^{\mathrm{c}}$ & $500^{c}$ & 22.1 & 371 & 34.9 \\
\hline 3 & Shigatse 1 & Agricultural soil & 29.321 & 89.164 & 3804 & $6.55^{c}$ & $433.3^{c}$ & 12.3 & 423 & 13.5 \\
\hline 4 & Shigatse 2 & Upland soil & 29.247 & 88.843 & 3910 & n.a. ${ }^{b}$ & n.a. & 16.0 & 236 & 9.4 \\
\hline 5 & Sangpei & Agricultural soil & 29.165 & 88.503 & 3956 & n.a. & n.a. & 19.2 & 236 & 9.3 \\
\hline 6 & Lhaze & Agricultural soil & 29.071 & 87.686 & 3992 & $6.77^{c}$ & $327.4^{c}$ & 27.0 & 176 & 19.9 \\
\hline 7 & Tingri & Upland soil & 28.628 & 87.170 & 4325 & $2.95^{\mathrm{c}}$ & $296.4^{c}$ & 16.3 & 127 & 7.7 \\
\hline 8 & Basum & Agricultural soil & 28.421 & 87.019 & 4160 & n.a. $/ 4.27^{d}$ & n.a. & 18.5 & 339 & 8.9 \\
\hline 9 & Ximu & Agricultural soil & 28.794 & 86.242 & 4458 & n.a./1.89d & n.a. & 16.3 & 139 & 4.3 \\
\hline 10 & Nyalam & Upland soil & 28.492 & 86.149 & 4823 & n.a. $/-1.03^{d}$ & n.a. & 19.1 & 162 & 6.3 \\
\hline 11 & $\mathrm{BC}$ & Moraine soil & 28.114 & 86.934 & 5302 & n.a. $/-4.87^{d}$ & n.a. & 3.1 & 70 & 5.9 \\
\hline 12 & East Rongbuk 1 & Upland soil & 28.103 & 86.874 & 5413 & n.a. $/-5.75^{d}$ & n.a. & 10.3 & 147 & 10.1 \\
\hline 13 & East Rongbuk 2 & Moraine soil & 28.085 & 86.914 & 5800 & n.a. $/-8.85^{d}$ & n.a. & 4.7 & 47 & 8.7 \\
\hline 14 & $\mathrm{MBC}$ & Moraine soil & 28.057 & 86.929 & 6050 & n.a. $/-10.9^{d}$ & n.a. & 2.0 & 80 & 6.0 \\
\hline 15 & $\mathrm{ABC}$ & Moraine soil & 28.035 & 86.943 & 6378 & n.a. $/-13.5^{d}$ & n.a. & 2.0 & 78 & 7.4 \\
\hline
\end{tabular}

a $\mathrm{m}$ a.s.l., Meters above sea level.

b n.a., Not available.

c The actual temperatures and precipitations were cited from Yang et al., (2006).

d The temperature was calculated with a decreasing gradient of $0.8^{\circ} \mathrm{C} / 100 \mathrm{~m}$ based on the actual temperature in Tingri $\left(2.95{ }^{\circ} \mathrm{C}\right)$. 
Table 2

The slope, linear regression coefficient $\left(r^{2}\right)$ and significance level $(p)$ for the correlation of $\log (\mathrm{POPs})$ vs. $\log (\mathrm{TOC})$ and $\log (\mathrm{POPs} / \mathrm{TOC})$ vs. $1 / T$.

\begin{tabular}{|c|c|c|c|c|c|c|c|c|}
\hline \multirow[t]{2}{*}{ Compound } & \multicolumn{3}{|c|}{$\log (\mathrm{POPs})$ vs. $\log (\mathrm{TOC})$} & \multicolumn{3}{|c|}{$\log (\mathrm{POPs} / \mathrm{TOC})$ vs. $1 / T^{\mathrm{a}}$} & \multirow[t]{2}{*}{$\triangle H\left(\mathrm{~kJ} \mathrm{~mol}^{-1}\right)$} & \multirow[t]{2}{*}{$P_{L}(\mathrm{~Pa})^{\mathrm{b}}$} \\
\hline & Slope & $r^{2}$ & $p$ & Slope & $r^{2}$ & $p$ & & \\
\hline PCB-28 & 0.397 & 0.44 & $<0.01$ & 3896 & 0.69 & $<0.05$ & 74.6 & $10^{-1.5}$ \\
\hline PCB-52 & 0.435 & 0.44 & $<0.01$ & 4004 & 0.65 & $<0.05$ & 76.6 & $10^{-1.8}$ \\
\hline PCB-101 & 0.416 & 0.45 & $<0.01$ & 4349 & 0.87 & $<0.01$ & 83.3 & $10^{-2.5}$ \\
\hline PCB-118 & 0.446 & 0.39 & $<0.05$ & 3901 & 0.65 & $<0.05$ & 74.7 & $10^{-3.0}$ \\
\hline PCB-123 & 0.546 & 0.4 & $<0.05$ & 3537 & 0.43 & $>0.05$ & 67.7 & \\
\hline PCB-138 & 0.501 & 0.46 & $<0.01$ & 4946 & 0.93 & $<0.01$ & 94.7 & $10^{-3.2}$ \\
\hline PCB-153 & 0.507 & 0.58 & $<0.01$ & 4295 & 0.88 & $<0.01$ & 82.2 & $10^{-3.3}$ \\
\hline PCB-156 & 0.458 & 0.29 & $<0.05$ & 4534 & 0.71 & $<0.05$ & 86.8 & \\
\hline PCB-167 & 0.59 & 0.42 & $<0.01$ & 3827 & 0.59 & $<0.05$ & 73.3 & \\
\hline PCB-180 & 0.255 & 0.26 & $>0.05$ & 5176 & 0.79 & $<0.01$ & 99.1 & $10^{-3.9}$ \\
\hline РСB-209 & 0.258 & 0.15 & $>0.05$ & 5049 & 0.61 & $<0.05$ & 96.7 & \\
\hline BDE-17 & 0.79 & 0.6 & $<0.01$ & 2572 & 0.5 & $>0.05$ & 49.3 & $10^{-1.8}$ \\
\hline BDE-28 & 0.791 & 0.52 & $<0.01$ & 3087 & 0.64 & $<0.05$ & 59.1 & $10^{-2.7}$ \\
\hline BDE-47 & 0.28 & 0.17 & $>0.05$ & 5581 & 0.8 & $<0.01$ & 106.8 & $10^{-3.7}$ \\
\hline BDE-66 & 0.302 & 0.1 & $>0.05$ & 7003 & 0.96 & $<0.01$ & 134.1 & $10^{-3.9}$ \\
\hline BDE-99 & 0.046 & 0.01 & $>0.05$ & 6071 & 0.91 & $<0.01$ & 116.2 & $10^{-4.8}$ \\
\hline BDE-100 & -0.131 & 0.07 & $>0.05$ & 7094 & 0.96 & $<0.01$ & 135.8 & $10^{-4.5}$ \\
\hline BDE-153 & 0.013 & 0 & $>0.05$ & 6530 & 0.95 & $<0.01$ & 125 & $10^{-5.7}$ \\
\hline BDE-154 & -0.479 & 0.21 & $>0.05$ & 7706 & 0.94 & $<0.01$ & 147.5 & $10^{-5.4}$ \\
\hline BDE-183 & -0.423 & 0.13 & $>0.05$ & 6540 & 0.91 & $<0.01$ & 125.2 & $10^{-6.3}$ \\
\hline
\end{tabular}

a The correlation of $\log$ (POPs/TOC) vs. $1 / T$ was only processed for the sampling sites above $4458 \mathrm{~m}$ a.s.l.

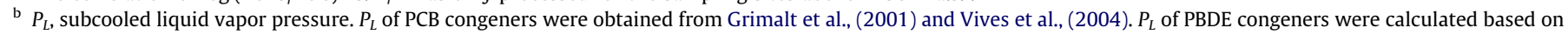
the date from Tittlemier et al., (2002).

phenomena was however not found in European high mountain lakes (no significant correlation $(p>0.05)$ between OCs and TOC) (Grimalt et al., 2004). While for PBDEs, only significant relationships were observed between log-transformed BDE-17 and 28 and $\log (\mathrm{TOC})(p<0.01)$. This is probably because heavier congeners have low volatility which makes most PBDE congeners less prone to undergo LRAT, and some of them could also be degraded in the environment. In addition, a significant linear relationship between the concentrations of $\sum$ PBDEs and $\sum$ PCBs (Fig. S3; $p<0.05$ ) reflected the similar distribution trend between PCBs and PBDEs in this area, which was in agreement with the results in fish from European high mountain lakes (Gallego et al., 2007).

\subsection{Altitude dependence and temperature correlation}

To examine the potential occurrence of POPs distillation in Tibetan Plateau, the TOC-normalized concentrations were log-transformed and then correlated with the altitudes of the sampling sites. As shown in Fig. 2, both the PCB and PBDE congeners found in all samples fitted a second order polynomial model very well $(p<0.05)$. From $3500 \mathrm{~m}$ a.s.l. to about $4500 \mathrm{~m}$ a.s.l., the concentrations showed an inverse relationship with the altitudes from the central plateau to the submontane region of Himalayas. Subsequently, a significantly positive dependence on altitudes above the inflexion indicated that higher TOC-normalized concentrations were found at the higher altitude sites. This observed altitude dependence corresponded very well with two different orographic characters in this region: spacious area but relatively small increment of altitudinal gradient of the plateau below $4500 \mathrm{~m}$ a.s.l., and steep altitudinal gradient in the Himalayas above $4500 \mathrm{~m}$ a.s.l. Some sampling sites were situated along the highway from the central plateau to the north of Himalayas, in regions where inhabitants conduct commerce activities and agricultural activities or animal grazing, which might change the distribution of POPs in the local environment. Especially in the urban areas, such as Lhasa and Shigatse, the influence from the relatively developed industries should not be ignored. In addition, the precipitation rates showed a decreasing trend from the central plateau to the Himalayas, but no interrelation was found between the perennial wind direction and the distribution trend of POPs. Therefore, the nega- tive dependence suggested that the distance from anthropogenic influence or potential pollution source and the precipitation rate should be the dominant influence factors rather than spatial gradient and perennial wind direction. This is in agreement with the common pollutant dilution pattern.

With regard to the positive altitude dependence in the Himalayan region, higher TOC-normalized concentrations in higher altitude sites is as predicted by the global distillation theory encompassing the transport of POPs from diffuse sources to the remote environment as a consequence of cold condensation (Daly and Wania, 2005), albeit in this case it is for high altitude areas rather than high latitude regions. Many other factors could also influence and enhance the contaminants accumulation in the cold regions, such as reduced degradation rates due to lower temperatures and the presence of precipitations, e.g., snow. However, the higher TOC-normalized concentrations could not be mainly attributed to the precipitations because of the rain shadow effect in the north of Himalayas, including the northern slope of Mt. Qomolangma. This cold condensation effect indicated inverse temperature dependence of both PCBs and PBDEs in this area. In respect to the fact that no meteorological data could be obtained for the sampling sites in the Himalayas, an absolute temperature was calculated with an average gradient of $-0.8^{\circ} \mathrm{C} / 100 \mathrm{~m}$ (Ye and Gao, 1979) based on the observed temperature of $2.95^{\circ} \mathrm{C}$ in Tingri (sampling site 7), a submontane town, and then correlated with the TOC-normalized concentrations (Table 2). The correlation of $\log (-$ POPs/TOC) vs. $1 / T$ was significantly positive, corresponding to the altitude dependence. This temperature dependence was also reported by other studies, involving compounds with vapor pressure lower than $10^{-2.5} \mathrm{~Pa}$ (Grimalt et al., 2001; Fernández and Grimalt, 2003; Vives et al., 2004); in one case, even lower than $10^{-3.0} \mathrm{~Pa}$ for PCBs and $10^{-4.2}$ Pa for PBDEs in fish from European high mountain lakes (Gallego et al., 2007). However, in this study, most congeners including PCB-28 and 52, of which the vapor pressure are higher than $10^{-2.5} \mathrm{~Pa}$, also showed this temperature dependence, which may suggest different mechanism for POPs between two exchange systems: air-soil and air-water-fish (or sediment).

As reported by previous studies, at low temperature $\left(<5^{\circ} \mathrm{C}\right)$ the concentrations of such compounds show no dependence on temperature and remained at a stable level in remote areas (Hoff 

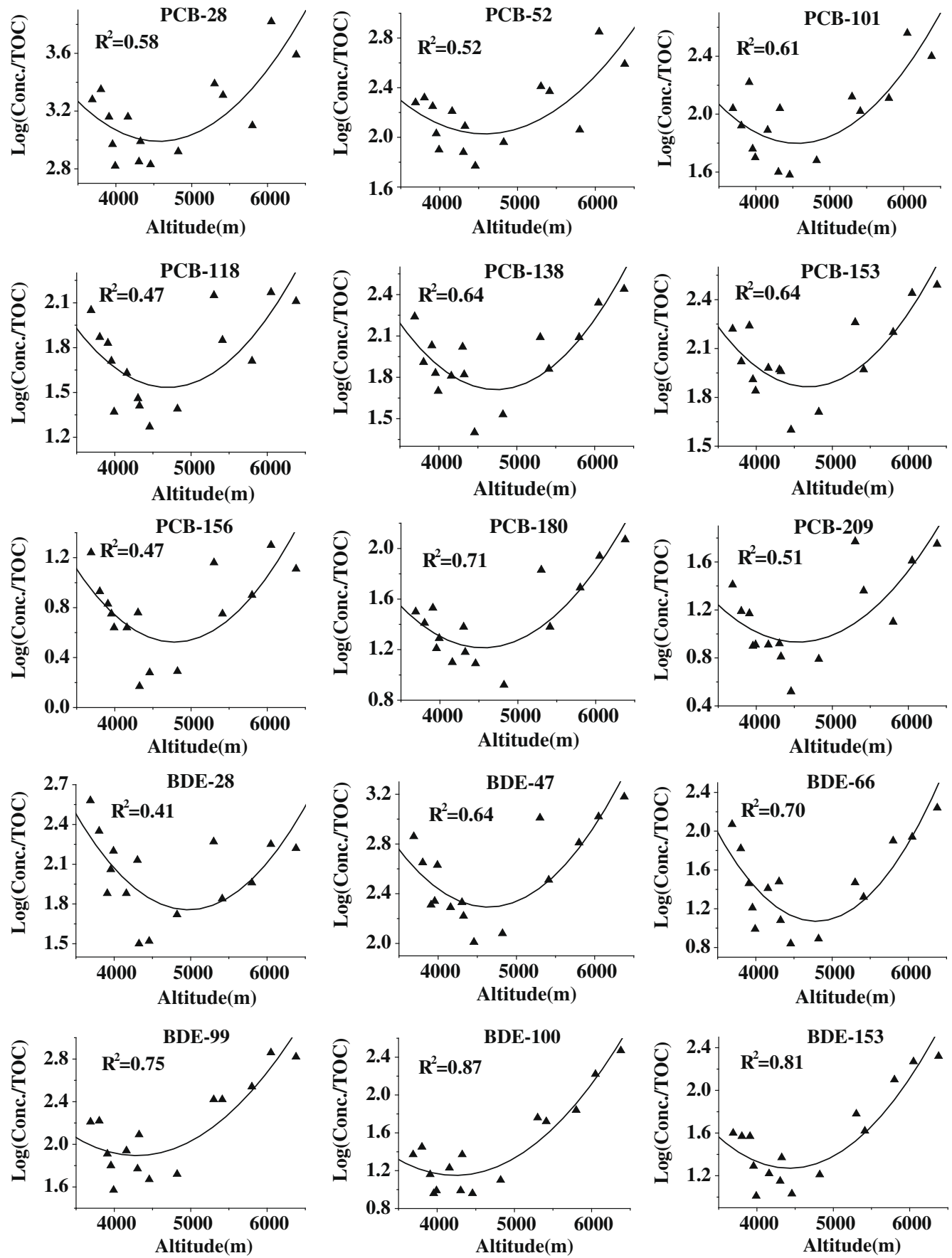

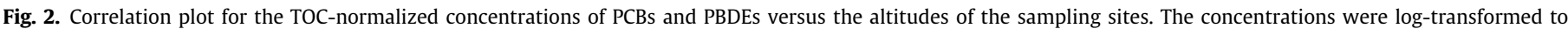
obtain normal distribution of the variables.

et al., 1998; Wania et al., 1998; van Drooge et al., 2002). In this case, a constant atmospheric concentration of the pollutant in the Himalayan region could be assumed. Further assessment on the environmental significance of the observed temperature dependences above $4458 \mathrm{~m}$ a.s.l. can be obtained by calculating the phase change pseudo-enthalpies (Grimalt et al., 2001; Ribes et al., 2002; Borghini et al., 2005):

$\Delta H=S * R * \ln (10)$

where $S$ is the slope of the regression line of $\log$ (POPs/TOC) vs. $1 / T$ and $R$ the gas constant, $8.314 \mathrm{~J} \mathrm{~K}^{-1} \mathrm{~mol}^{-1}$. As listed in Table 2, the values of $\Delta H$ for PCBs ranged from 73 to $99 \mathrm{~kJ} \mathrm{~mol}^{-1}$, with the exception of $67.7 \mathrm{~kJ} \mathrm{~mol}^{-1}$ for PCB-123 of which the temperature dependence was not significant $(p>0.05)$. These field constants were consistent with the enthalpies of phase change from octanol-air calculated in laboratory experiments, $71-93 \mathrm{~kJ} \mathrm{~mol}^{-1}$ (Harner and Bidleman, 1996; Kömp and Mclachlan, 1997). However, due to significant regression coefficients and large slopes of regression lines (Table 2), most of $\Delta H$ for PBDEs were slightly higher than the theoretical values $\left(72.8-107 \mathrm{~kJ} \mathrm{~mol}^{-1}\right.$, Harner and Shoeib, 2002), except for BDE-17 and 28 (no significant correlation with the reciprocal of temperature $(p>0.05))$, both of which were lower than the theoretical ranges. As demonstrated in previous researches (Ribes et al., 2002; Borghini et al., 2005), the comparison of the two types of values should be carried out with caution because they were obtained under two different temperature conditions: 
laboratorial environment and field atmosphere condition. Even so, the high phase change pseudo-enthalpies observed in Himalayan soil provide evidence for the occurrence of cold condensation effect other than simple linear adsorption, and the higher values obtained from the field data indicate that the intensity of this effect is related to atmosphere temperature, being more relevant at low values.

Interestingly, as shown in Figs. S1 and S2, increasing levels of higher chlorinated and brominated congeners were found in the higher altitude sites although the lighter congeners were the main components. This could be confirmed by the magnification of the TOC-transformed concentration along the increasing altitude (Fig. 2). For the lighter congeners, only 4- or 5-fold increase of soil concentration was observed between the altitudes of $4458 \mathrm{~m}$ a.s.l and $6378 \mathrm{~m}$ a.s.l. However, it became larger for the heavier congeners, reaching 13-fold for PCB-180 and even up to 30-fold for BDE-100 and 153. In order to investigate this trend of magnification along increasing altitude, a theoretical magnification factor $\left(M_{F}\right)$ was defined as follows:

$\log \left(M_{F}\right)=C_{\text {TOC,6378 m }}-C_{\text {TOC, } 4458 \mathrm{~m}}$

where $C_{\mathrm{TOC},} 6378 \mathrm{~m}$ and $C_{\mathrm{TOC}} 4458 \mathrm{~m}$ are the log-transformed TOC-normalized concentrations which were calculated based on the regression linear function of $\log$ (POPs/TOC) vs. 1/T between $4458 \mathrm{~m}$ a.s.l. and $6378 \mathrm{~m}$ a.s.l. (Table S4). As shown in Fig. 3, a significant linear relationship $(p<0.0001)$ was found between log-transformed subcooled liquid vapor pressures $\left(V_{P}\right)$ and $\log \left(M_{F}\right)$, and less volatile congener with lower vapor pressure showed larger magnification. This reversed tendency suggested that the less volatile compounds seem to become enriched easier than the more volatile constituents at the higher altitude site, despite the proportion of the heavier congener was much less than the lighter. This is consistent with the investigation from the mountain soils of Western Sichuan, China (Chen et al., 2008) and the simulation study by Wania and Westgate (2008), but opposite from the observation of OCs in mountains of western Canada (Blais et al., 1998). Considering the extremely complex environment at such high altitude, the deposition and revolatilization of the lighter POPs were influenced significantly by the strong wind besides the cold condensation effect. It is therefore worth to study the interrelation between altitude dependence of semi-volatile contaminants and their vapor pressures in such high altitude regions.

It is noteworthy that the similar altitude dependence along the mountain slope were observed for PAHs in soil (Wang et al., 2007a), Himalayan spruce needle (Wang et al., 2006), and organochlorine pesticides (OCPs) in soil, grasses (Wang et al., 2007b) and

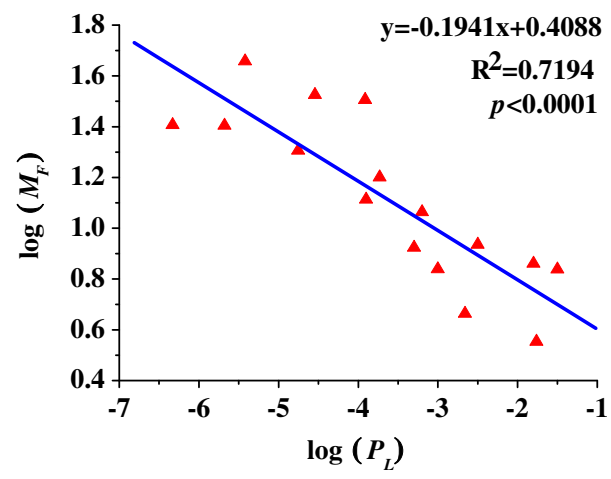

Fig. 3. Correlation plot for the magnification factors $\left(M_{F}\right)$ of the concentrations versus subcooled liquid vapor pressures $\left(P_{L}\right)$ of PCB and PBDE congeners. $P_{L}$ values were collected for PCB-28, 52, 101, 118, 138, 153 and 180 (Grimalt et al., 2001; Vives et al., 2004), BDE-17, 28, 47, 66, 99, 100, 153, 154 and 183 (Tittlemier et al., 2002). Both the $M_{F}$ and $P_{L}$ were log-transformed to obtain a normal distribution of the variables. snow (Wang et al., 2007c), but different interpretations were put forth. (Wang et al., 2006, 2007a,b) indicated that several heavy PAHs and OCPs with relatively low long-range transport potential reached high altitude sampling sites, suggesting that there were emission sources close to the sampling sites. Wang et al., 2007c also considered the close distance between the sampling sites and the pollution sources was the most important influence factor for that observation in the fresh-fallen snow from East Rongbuk Glacier. However, as presented in this study, the altitude dependence of PCBs and PBDEs in the soil from Himalayas was observed under aforementioned complex environment but irrespectively of PCBs and PBDEs source. Therefore, this observation provided further evidence to the hypothesis of the global distillation effect, as a consequence of cold condensation at high altitude and low temperature.

\section{Acknowledgements}

This study was jointly supported by the National Hi-tech Research and Development Program of China (2007AA061601), National Natural Science Foundation of China (20777079, 20897011 and 20621703), and National Basic Research Program of China (2009CB421600). We are indebted to the Institute of Tibetan Plateau Research, Chinese Academy of Sciences for field assistance.

\section{Appendix A. Supplementary material}

Supplementary data associated with this article can be found, in the online version, at doi:10.1016/j.chemosphere.2009.06.045.

\section{References}

Blais, J.M., Schindler, D.W., Muir, D.C.G., Kimpe, L.E., Donald, D.B., Rosenberg, B., 1998. Accumulation of persistent organochlorine compounds in mountains of western Canada. Nature 395, 585-588.

Borghini, F., Grimalt, J.O., Sanchez-Hernandez, J.C., Barra, R., Torres García, C.J., Focardi, S., 2005. Organochlorine compounds in soils and sediments of the mountain Andean Lakes. Environ. Pollut. 136, 253-266.

Chen, D.Z., Liu, W.J., Liu, X.D., Westgate, J.N., Wania, F., 2008. Cold-trapping of persistent organic pollutants in the mountain soils of western Sichuan, China. Environ. Sci. Technol. 42, 9086-9091.

Clausen, J., Berg, O., 1975. The content of polychlorinated hydrocarbons in Arctic ecosystems. Pure Appl. Chem. 42, 223-232.

Daly, G.L., Wania, F., 2005. Organic contaminants in mountains. Environ. Sci. Technol. 39, 385-398.

de Wit, C.A., Alaee, M., Muir, D.C.G., 2006. Brominated flame retardants in the Arctic. Chemosphere 64, 209-233.

Fernández, P., Grimalt, J.O., 2003. On the global distribution of persistent organic pollutants. Chimia 57, 514-521.

Gallego, E., Grimalt, J.O., Bartrons, M., Lopez, J.F., Camarero, L., Catalan, J., 2007. Altitudinal gradients of PBDEs and PCBs in fish from European high mountain lakes. Environ. Sci. Technol. 41, 2196-2202.

George, J.L., Frear, D.E.H., 1966. Pesticides in the Antarctic. J. Appl. Ecol. 3, 155-167.

Gregor, D.J., Gummer, W.D., 1989. Evidence of atmospheric transport and deposition of organochlorine pesticides and polychlorinated biphenyls in Canadian Arctic snow. Environ. Sci. Technol. 23, 561-565.

Grimalt, J.O., Fernandez, P., Berdie, L., Vilanova, R.M., Catalan, J., Psenner, R., Hofer, R., Appleby, P.G., Rosseland, B.O., Lien, L., Massabuau, J.C., Battarbee, R.W., 2001. Selective trapping of organochlorine compounds in mountain lakes of temperate areas. Environ. Sci. Technol. 35, 2690-2697.

Grimalt, J.O., van Drooge, B.L., Ribes, A., Vilanova, R.M., Fernandez, P., Appleby, P., 2004. Persistent organochlorine compounds in soils and sediments of European high altitude mountain lakes. Chemosphere 54, 1549-1561.

Harner, T., Bidleman, T.F., 1996. Measurements of octanol-air partition coefficients for polychlorinated biphenyls. J. Chem. Eng. Data 41, 895-899.

Harner, T., Shoeib, M., 2002. Measurements of octanol-air coefficients $\left(K_{\mathrm{OA}}\right)$ for polybrominated diphenyl ethers (PBDEs): predicting partitioning in the environment. J. Chem. Eng. Data 47, 228-232.

Hassanin, A., Breivik, K., Meijer, S.N., Steinnes, E., Thomas, G.O., Jones, K.C., 2004. PBDEs in European background soils: levels and factors controlling their distribution. Environ. Sci. Technol. 38, 738-745.

Hoff, R.M., Brice, K.A., Halsall, C.J., 1998. Nonlinearity in the slopes of ClausiusClapeyron plots for SVOCs. Environ. Sci. Technol. 32, 1793-1798.

Ikonomou, M.G., Rayne, S., Addison, R.F., 2002. Exponential increases of the brominated flame retardants, polybrominated diphenyl ethers, in the Canadian Arctic from 1981 to 2000. Environ. Sci. Technol. 36, 1886-1892. 
Kömp, P., Mclachlan, M., 1997. Octanol/air partitioning of polychlorinated biphenyls. Environ. Toxicol. Chem. 16, 2433-2437.

Liu, H.X., Zhang, Q.H., Cai, Z.W., Li, A., Wang, Y.W., Jiang, G.B., 2006. Separation of polybrominated diphenyl ethers, polychlorinated biphenyls, polychlorinated diebenzo-p-dioxins and dibenzo-furans in environmental samples using silica gel and florisil fractionation chromatography. Anal. Chim. Acta 557, 314-320.

Loewen, M.D., Sharma, S., Tomy, G., Wang, F., Bullock, P., Wania, F., 2005. Persistent organic pollutants and mercury in the Himalaya. Aquat. Ecosyst. Health Manage. 8, 223-233.

Meijer, S.N., Ockenden, W.A., Seetman, A., Breivik, K., Grimalt, J.O., Jones, K.C., 2003. Global distribution and budget of PCBs and HCB in background surface soils: implications for sources and environmental processes. Environ. Sci. Technol. 37, 667-672.

Ren, N.Q., Que, M.X., Li, Y.F., Liu, Y.F., Wan, X.N., Xu, D.D., 2007. Polychlorinated biphenyls in Chinese surface soils. Environ. Sci. Technol. 41, 3871-3876.

Ribes, A., Grimalt, J.O., Torres Garcia, C.J., Cuevas, E., 2002. Temperature and organic matter dependence of the distribution of organochlorine compounds in mountain soils from the subtropical Atlantic (Teide, Tenerife Island). Environ. Sci. Technol. 36, 1879-1885.

Shen, H.Q., Henkelmann, B., Levy, W., Zsolnay, A., Weiss, P., Jakobi, G., Kirchner, M., Moche, W., Braun, K., Schramm, K., 2009. Altitudinal and chiral signature of persistent organochlorine pesticides in air, soil, and spruce needles (Picea abies) of the Alps. Environ. Sci. Technol. 43, 2450-2455.

Simonich, S.L., Hites, R.A., 1995. Global distribution of persistent organochlorine compounds. Science 269, 1851-1854.

Tittlemier, S.A., Halldorson, T., Stern, G.A., Tomy, G.T., 2002. Vapor pressure, aqueous solubilities, and Henry's law constants of some brominated flame retardants. Environ. Toxicol. Chem. 21, 1804-1810.

van Drooge, B.L., Grimalt, J.O., Torres Garcia, C.J., Cuevas, E., 2002. Semivolatile organochlorine compounds in the free troposphere of the northeastern Atlantic. Environ. Sci. Technol. 36, 1155-1161.
Vives, I., Grimalt, J.O., Catalan, J., Rosseland, B.O., Battarbee, R.W., 2004. Influence of altitude and age in the accumulation of organochlorine compounds in fish from high mountain lakes. Environ. Sci. Technol. 38, 690-698.

Wang, X.P., Yao, T.D., Cong, Z.Y., Yan, X.L., Kang, S.C., Zhang, Y., 2006. Gradient distribution of persistent organic contaminants along northern slope of centralHimalayas, China. Sci. Total. Environ. 372, 193-202.

Wang, X.P., Yao, T.D., Cong, Z.Y., Yan, X.L., Kang, S.C., Zhang, Y., 2007a. Concentration level and distribution of polycyclic aromatic hydrocarbons in soil and grass around Mt. Qomolangma, China. Chinese Sci. Bull. 52, 1405-1413.

Wang, X.P., Yao, T.D., Cong, Z.Y., Yan, X.L., Kang, S.C., Zhang, Y., 2007b. Distribution of persistent organic pollutants in soil and grasses around Mt. Qomolangma, China. Arch. Environ. Con. Tox. 52, 153-162.

Wang, F., Zhu, T., Xu, B.Q., Kang, S.C., 2007c. Organochlorine pesticides in freshfallen snow on East Rongbuk Glacier of Mt. Qomolangma (Everest). Sci. China Ser. D 50, 1097-1102.

Wania, F., Mackay, D., 1993. Global fractionation and cold condensation of low volatility organochlorine compounds in Polar Regions. Ambio 22, 10 18.

Wania, F., Westgate, J.N., 2008. On the mechanism of mountain cold-trapping of organic chemicals. Environ. Sci. Technol. 42, 9092-9098.

Wania, F., Haugen, J.E., Lei, Y.D., Mackay, D., 1998. Temperature dependence of atmospheric concentrations of semivolatile organic compounds. Environ. Sci. Technol. 32, 1013-1021.

Yang, X.C., Zhang, Y.L., Zhang, W., Yan, Y.P., Wang, Z.F., Ding, M.J., Chu, D., 2006 Climate change in Mt. Qomolangma region in China during the last 34 years. Acta. Geogr. Sin. 61, 687-696.

Yang, R.Q., Yao, T.D., Xu, B.Q., Jiang, G.B., Xin, X.D., 2007. Accumulation features of organochlorine pesticides and heavy metals in fish from high mountain lakes and Lhasa River in the Tibetan Plateau. Environ. Int. 33, 151-156.

Ye, D.Z., Gao, Y.X., 1979. Meteorology of the Tibetan Plateau. Science Press, Beijing 